\title{
A modeling approach to estimate the solar disinfection of viral indicator organisms in waste stabilization ponds and surface waters
}

\author{
Tamar Kohn ${ }^{\text {a }}$, Michael J. Mattle a, Marco Minella ${ }^{\text {b }}$, Davide Vione ${ }^{\text {b, * }}$ \\ ${ }^{a}$ Laboratory of Environmental Chemistry, School of Architecture, Civil and Environmental Engineering (ENAC), École Polytechnique Fédérale de Lausanne \\ (EPFL), CH-1015 Lausanne, Switzerland \\ b Dipartimento di Chimica, Università degli Studi di Torino, Via P. Giuria 5, 10125, Torino, Italy
}

\section{A R T I C L E I N F O}

\section{Article history:}

Received 8 October 2015

Accepted 7 November 2015

Available online 11 November 2015

\section{Keywords:}

APEX

Solar disinfection model

Virus inactivation

Waste stabilization pond

\begin{abstract}
A B S T R A C T
Sunlight is known to be a pertinent factor governing the infectivity of waterborne viruses in the environment. Sunlight inactivates viruses via endogenous inactivation (promoted by absorption of solar light in the UVB range by the virus) and exogenous processes (promoted by adsorption of sunlight by external chromophores, which subsequently generate inactivating reactive species). The extent of inactivation is still difficult to predict, as it depends on multiple parameters including virus characteristics, solution composition, season and geographical location. In this work, we adapted a model typically used to estimate the photodegradation of organic pollutants, APEX, to explore the fate of two commonly used surrogates of human viruses (coliphages MS2 and $\phi X 174$ ) in waste stabilization pond and natural surface water. Based on experimental data obtained in previous work, we modeled virus inactivation as a function of water depth and composition, as well as season and latitude, and we apportioned the contributions of the different inactivation processes to total inactivation. Model results showed that $\phi \times 174$ is inactivated more readily than MS2, except at latitudes $>60^{\circ}$. $\phi X 174$ inactivation varies greatly with both season ( 20 -fold) and latitude ( 10 -fold between 0 and $60^{\circ}$ ), and is dominated by endogenous inactivation under all solution conditions considered. In contrast, exogenous processes contribute significantly to MS2 inactivation. Because exogenous inactivation can be promoted by longer wavelengths, which are less affected by changes in season and latitude, MS2 exhibits smaller fluctuations in inactivation throughout the year ( 10 -fold) and across the globe (3-fold between 0 and $60^{\circ}$ ) compared to $\phi X 174$. While a full model validation is currently not possible due to the lack of sufficient field data, our estimated inactivation rates corresponded well to those reported in field studies. Overall, this study constitutes a step toward estimating microbial water quality as a function of spatio-temporal information and easy-todetermine solution parameters.
\end{abstract}

() 2015 Elsevier Ltd. All rights reserved.

\section{Introduction}

The discharge of wastewater or untreated human waste into the environment leads to the continuous input of enteric viruses into surface water (Okoh et al., 2010; Simmons and Xagoraraki, 2011). Once in the environment, the infectivity of enteric viruses is compromised by various environmental stressors, including exposure to sunlight, temperature fluctuations, or predation by microorganisms (Fong and Lipp, 2005). Sunlight is known to be particularly effective at reducing virus infectivity, and this property has been exploited for the design of effective natural wastewater

\footnotetext{
* Corresponding author.

E-mail address: davide.vione@unito.it (D. Vione).
}

treatment systems, such as waste stabilization ponds (WSPs, also known as waste treatment ponds or treatment lagoons) (DaviesColley et al., 1999, 2000). The processes involved in the solar disinfection, or photoinactivation, of viruses in environmental waters are now fairly well understood (Davies-Colley et al., 1999; Kohn and Nelson, 2007; Mattle et al., 2015; Silverman et al., 2013; Sinton et al., 2002). Yet, we are only just beginning to integrate this information into a quantitative framework that allows the prediction of disinfection efficiencies in WSPs, or of inactivation rates in sunlight-exposed surface waters systems. Such predictive models, however, are instrumental for optimizing the design of natural treatment systems, and assess the water quality of drinking water sources and recreational waters, and to assess risks for water reuse planning (UN, 2015). 
Photoinactivation of viruses occurs by two distinct processes, endogenous (direct or indirect) and exogenous (only indirect) inactivation (Davies-Colley et al., 1999). Endogenous inactivation is mediated by virus-internal chromophores, such as the nucleic acid or aromatic amino acids in the protein coat, which absorb light in the solar range. Upon light excitation, these internal chromophores can degrade and cause the virus to become inactivated. This process is referred to as direct inactivation. Alternatively, endogenous inactivation can occur in an indirect fashion. Hereby, the excited chromophores transfer energy or electrons to dissolved oxygen or other solution constituents, which leads to the formation of a variety of transient reactive species (e.g., singlet oxygen). Along with the excited chromophores themselves, these reactive species can then oxidize surrounding virus constituents and thereby cause inactivation. While direct and indirect endogenous inactivation occur simultaneously, direct sunlight inactivation of viruses (F-DNA phages) has been shown to be efficient, whereas indirect endogenous inactivation was of minor importance (Davies-Colley et al., 1999). It can thus be assumed that endogenous inactivation mainly occurs in a direct manner.

In indirect exogenous inactivation, reactive species are produced by virus-independent chromophores present in solution. In natural waters, they include chromophoric dissolved organic matter (CDOM), nitrate or nitrite, which can contribute to the production of several reactive species ( $\mathrm{OH}, \mathrm{CO}_{3}{ }^{-\cdot},{ }^{1} \mathrm{O}_{2}$ and $\mathrm{CDOM}$ triplet states, ${ }^{3} \mathrm{CDOM}^{*}$ ) (Boule et al., 2005). The efficiency of exogenous inactivation is thus strongly dependent on the characteristics and photoreactivity of the solution (Carratalà et al., submitted; Silverman et al., 2013). In addition, the contribution of the exogenous process to total inactivation depends strongly on the virus under consideration. For example, exogenous inactivation significantly contributed to the photoinactivation of human adenovirus (Silverman et al., 2013), human rotavirus (Romero-Maraccini et al., 2013), human echovirus (Carratalà et al., submitted), phages PRD1 and MS2 (Kohn and Nelson, 2007; Silverman et al., 2013) and native F-RNA phages (Davies-Colley et al., 1999; Sinton et al., 2002). In contrast, its importance was only minor in the solar inactivation of poliovirus (Silverman et al., 2013), porcine rotavirus (Romero et al., 2011; Romero-Maraccini et al., 2013), and native F+ DNA phages (Davies-Colley et al., 1999; Sinton et al., 2002).

In recent work, we have demonstrated that the total photoinactivation of two commonly used surrogates of human viruses, phages MS2 and $\phi X 174$, can be estimated by simply summing up the contributions of endogenous and exogenous inactivation (Mattle et al., 2015). Specifically, we formulated the following model:

$\frac{d C_{\text {virus }}}{d t}=-k_{\text {virus }}^{0} C_{\text {virus }}=-P_{a}^{\text {virus }} \Phi_{\text {virus }}-\sum_{x} k_{\text {virus }, x} C_{s s, x} C_{\text {virus }}$

$C_{\text {virus }}=C_{\text {virus }, 0} e^{-k_{\text {virus }}^{0} t}$

Hereby the subscript "virus" is a placeholder for "MS2" or " $\phi X 174$ ". $C_{\text {virus }}$ and $C_{\text {virus }, 0}$ are the infective virus concentrations at times $\mathrm{t}$ and 0 respectively, and $k_{\text {virus }}^{0}$ is the first-order photoinactivation rate constant. The term $-P_{a}^{\text {virus }} \Phi_{\text {virus }}$ quantifies the direct endogenous inactivation $\left(=-k^{0}{ }_{\text {endo }} C_{\text {virus }}\right)$, with $\Phi_{\text {virus }}$ being the virus-dependent photoinactivation quantum yield (number of viruses inactivated/number of photons absorbed by the virus), and $P_{a}$ the photon flux absorbed by the virus. The second term of eq. (1a) describes the contribution of exogenous inactivation, whereby four relevant reactive species $x$ were considered: singlet oxygen $\left({ }^{1} \mathrm{O}_{2}\right)$, hydroxyl radical $\left({ }^{\circ} \mathrm{OH}\right)$, carbonate radical $\left(\mathrm{CO}_{3}{ }^{-\cdot}\right)$ and excited (triplet state) chromophoric dissolved organic matter $\left({ }^{3} \mathrm{CDOM}^{*}\right)$. It was found that virus inactivation by these reactive species can be described by apparent second-order kinetics, where $k_{\text {virus, } x}$ is the second-order inactivation rate constant, and $C_{s s, x}$ is the steady-state concentration of the reactive species under consideration. The experimental methods used to obtain the model parameters are described elsewhere (Mattle et al., 2015). This approach successfully predicted the inactivation of MS2 and $\phi X 174$ in laboratory experiments using WSP water and a solar simulator. In contrast, the inactivation of human adenovirus was less accurate, and was underestimated two-fold.

Silverman et al. (2015) pursued a similar approach. This group also considered total solar inactivation as the sum of endogenous and exogenous processes. However, the approach proposed by Silverman et al. differed from ours in two aspects: first, instead of a virus-dependent quantum yield, they used a virus- and wavelength-dependent sensitivity coefficient to describe endogenous inactivation. Second, rather than considering different reactive species individually, they considered inactivation by singlet oxygen as a proxy for all exogenous processes. Using these assumptions, they were able to estimate the inactivation of MS2 observed in lab experiments and an open-water wetland.

A limitation of the models used thus far is that they focused on the context of a specific solution, water body, and geographic location. Here, we exploit our model to expand our predictions of photoinactivation rates to a range of conditions. Specifically, we model the inactivation of MS2 and $\phi X 174$ as a function of water depth, geographic setting (in terms of latitude), season, and water characteristics. The combination of these two viruses is ideally suited to explore the boundaries of photoinactivation, as they exhibit opposite sensitivities to endogenous and exogenous processes: MS2 is sensitive to exogenous inactivation but not too sensitive to endogenous inactivation, whereas $\phi \mathrm{X} 174$ is very sensitive to endogenous inactivation but resistant to exogenous inactivation (Mattle et al., 2015; Sommer et al., 2001). Finally, we compare our model output to published data on solar disinfection, to demonstrate our model's general applicability.

\section{Methods}

\subsection{Photochemical modeling}

The model assessment of virus photoinactivation was carried out with the APEX software (Aqueous Photochemistry of Environmentally-occurring Xenobiotics; available for free download as Electronic Supplementary Information of Bodrato and Vione, 2014), which predicts photochemical reaction kinetics from photoreactivity parameters (quantum yields and secondorder reaction rate constants with reactive species) and from data of water chemistry and depth (Bodrato and Vione, 2014; Vione, 2014). APEX is based on a photochemical model, validated by comparison with field data of phototransformation kinetics in surface freshwaters (De Laurentiis et al., 2013; Maddigapu et al., 2011; Marchetti et al., 2013).

The absorption of radiation by the photosensitizers (CDOM, nitrate and nitrite) and the studied substrates is computed by taking into account competition for sunlight irradiance in a Lambert-Beer approach (Bodrato and Vione, 2014; Braslavsky, 2007). APEX applies to well-mixed waters and its results are average values over the water column. Therefore, they include the contributions of the well-illuminated surface layer and of darker water at the lower depths (Loiselle et al., 2008).

The solar spectrum was obtained for fair-weather conditions. For summer and seasonal data at mid-latitude, we used the standard APEX spectra that are taken from Frank and Klöpffer (1988). Data as a function of latitude were obtained with the NCAR-TUV 
calculator (National Center for Atmospheric Research, 2015).

Sunlight irradiance is not constant in the natural environment, because of meteorological variability (not included in APEX) and of diurnal and seasonal cycles. To allow easier comparison between model results and environmental conditions, APEX uses a summer sunny day (SSD) as a time unit, equivalent to fair-weather 15 July at $45^{\circ} \mathrm{N}$ latitude. An exception is represented by the APEX_Season function, which computes monthly trends of photoreaction kinetics. The time unit in the APEX_Season output is days of the relevant month. An additional exception is represented by data as a function of latitude for the spring equinox (see below). The reason for choosing the spring equinox in that case is that the sun is highest at the equator on the spring (and fall) equinox, while on different days of the year it is highest elsewhere in the tropical belt (e.g., at the Tropic of Cancer on the summer solstice and the Tropic of Capricorn on the winter one) (Montenbruck and Pfleger, 1994). Therefore, to avoid the occurrence of maxima in the virus photoinactivation plots as a function of the latitude (the occurrence of which would depend on the arbitrary choice of the reference day), and considering that the equator is the location on earth where (when excluding weather-related issues) the year-averaged solar irradiance is the highest, the spring equinox was taken as the reference time unit.

The uncertainties associated with the modeled parameters were determined using the APEX_Errors function.

\subsection{Input data}

The modeling work is based on experimental data of endogenous and exogenous photoinactivation of the phages MS2 and $\phi X 174$, which has been assessed in the laboratory under different conditions and in the presence of WSP water (obtained from Vuiteboeuf, Switzerland) under simulated sunlight (Mattle et al., 2015). Table 1 reports a summary of the experimental results, including the virus photoreactivity parameters (photoinactivation quantum yields $\Phi_{\text {virus }}$, second-order rate constants $k_{\text {virus }, x}$ with the reactive species $x={ }^{\circ} \mathrm{OH}, \mathrm{CO}_{3}{ }^{-\cdot},{ }^{1} \mathrm{O}_{2}$ and ${ }^{3} \mathrm{CDOM}^{*}$, first-order inactivation rate constants $k_{\text {virus }}^{o}$ of the viruses in WSP water). The Table also reports the chemical parameters of photochemical significance of the WSP water used in the experiments, and the steady-state

\section{Table 1}

Summary of the experimental data obtained by Mattle et al. (2015). Virus photoreactivity parameters, chemical composition of WSP water, steady-state concentration of reactive species. The optical path length of the solutions, irradiated under simulated sunlight, was $b=1.6 \mathrm{~cm}$. The error bounds represent $95 \%$ confidence intervals.

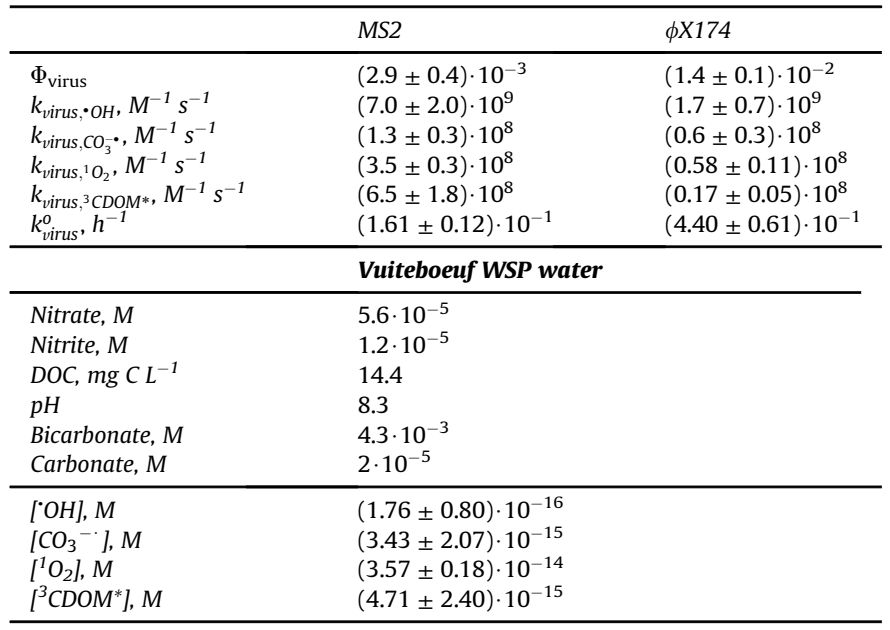

concentrations $C_{s s, x}$ of the reactive species under simulated sunlight. The WSP water absorption spectrum $\left(\alpha_{1}(\lambda)\right.$, referred to an optical path length $b=1 \mathrm{~cm})$ is reported in Fig. 1 together with the spectral photon flux densities $\left(p^{\circ}(\lambda)\right)$ of the solar simulator and of sunlight used for modeling.

\section{Results and discussion}

\subsection{Model calibration and evaluation}

In a first step, we assessed if APEX can estimate the experimentally observed virus photoinactivation kinetics, determined in WSP water irradiated by simulated sunlight $\left(k_{v i r u s}^{o}\right)$, as well as the measured steady-state concentrations of the photochemically produced reactive species ( $\left.\mathrm{O} \mathrm{OH}, \mathrm{CO}_{3}{ }^{-\cdot},{ }^{1} \mathrm{O}_{2},{ }^{3} \mathrm{CDOM}^{*}\right)$. The calibration of the model against experimental results was based on virus photoreactivity parameters $\left(\Phi_{\text {virus }}\right.$ and $\left.k_{\text {virus }, x}\right)$, the water chemistry data shown in Table 1, formation quantum yields and decay constants of reactive species in WSP water (reported in Mattle et al., 2015), and the water absorption spectrum $\left(\alpha_{1}(\lambda)\right)$ shown in Fig. 1. Computations also used an optical path length $b=1.6 \mathrm{~cm}$, which corresponded to the water column depth in the experimental cells (Mattle et al., 2015), as well as the $p^{\circ}(\lambda)$ of the solar simulator (see Fig. 1).

A good agreement between experimental and calculated photoinactivation rate constants $\left(k_{\text {virus }}^{o}\right)$ was obtained (see Appendix A, Table A1). This reflects the good accuracy by which the known endogenous and exogenous photo processes were able to account for the inactivation of both MS2 and $\phi X 174$ in WSP water. These results furthermore suggest that there are no significant biases in the APEX calculation procedures and in the measure units of virusrelated quantities.

In a second step, we evaluated a critical assumption used in our model, namely the use of a constant photoinactivation quantum yield $\Phi$ to estimate direct endogenous inactivation (see eq. (1a)). A constant quantum yield implies that each photon absorbed by the viral genome is equally effective at causing inactivation, independent of its wavelength. Therefore, our model assumes that the wavelength-dependence of direct endogenous inactivation arises solely from the fact that the viral genome absorbs differently at different wavelengths. In contrast, Silverman et al. (2015) accounted for the fact that photons at different wavelengths may differ in their inactivation efficiency. While such differences have been reported (e.g., Fisher et al., 2011), our approach assumed that they are

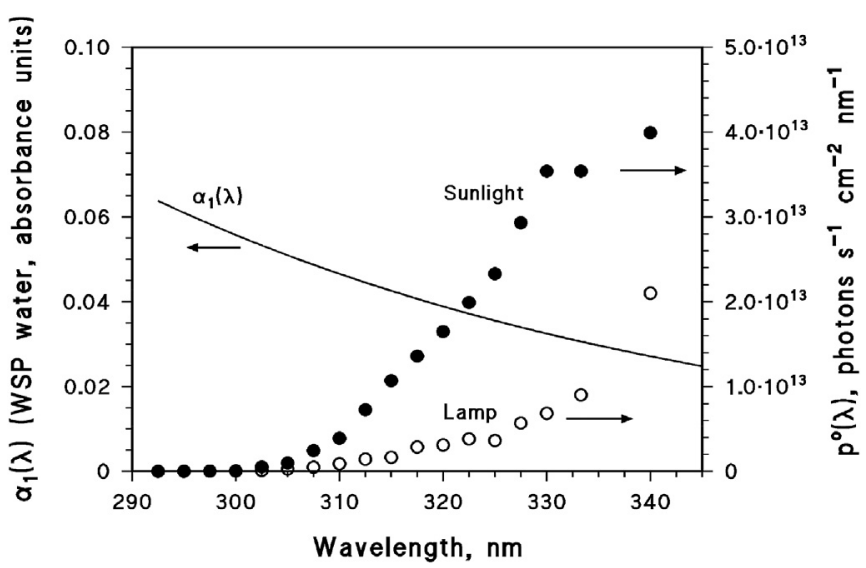

Fig. 1. Input data for APEX model. Absorption spectrum $\left(\alpha_{1}(\lambda), b=1 \mathrm{~cm}\right)$ of the WSP water. Incident spectral photon flux density $\left(p^{\circ}(\lambda)\right)$ of the solar simulator (lamp) (Mattle et al., 2015) and of sunlight used for modeling (Frank and Klöpffer, 1988). 
negligible over the solar UVB range. To verify that this assumption is valid, we substituted the constant quantum yield $\Phi_{\text {virus }}$ in eq. (1a) by a wavelength-dependent one $\left(\Phi_{\text {virus }}(\lambda)\right)$, and compared the model output of the two approaches.

The detailed wavelength trend of $\Phi_{\text {virus }}(\lambda)$ is unfortunately not known. However, quantum yields obtained for a range of viruses showed a decreasing trend with increasing wavelengths in the UVB range (Rauth, 1965). This behavior can be parameterized using a reasonably simple function:

$\Phi_{\text {virus }}(\lambda)=\psi \frac{10^{-A \lambda}}{10^{-A \lambda}+10^{-A B}}$

where $A$ measures the rate of decrease of $\Phi_{\text {virus }}(\lambda)$ with increasing wavelength, and $B$ defines the wavelength value at which the decrease is centered. Of course, whatever the wavelength trend of $\Phi_{\text {virus }}(\lambda)$, it has to be consistent with our experimental data of endogenous virus inactivation under the solar simulator (Mattle et al., 2015). Therefore the normalization factor $\psi$ scales $\Phi(\lambda)$ such that the model output matches the experimental data of endogenous inactivation rate constants $\left(k_{\text {virus }}^{\text {endo }}\right)$. This latter parameter was determined in solutions free of external sensitizers, such that inactivation only occurred by endogenous processes and $k^{0}$ virus $=$ $k^{\text {endo }}{ }_{\text {virus }}$ (Mattle et al., 2015).

Eight different cases of $\Phi_{M S 2}(\lambda)$ and $\Phi_{\phi X 174}(\lambda)$ based on different values of $A$ and $B$ are shown in Fig. 2. Cases 4 and 8 are step functions with a constant $\Phi$ below $300 \mathrm{~nm}$ (4) or $310 \mathrm{~nm}(8)$, and $\Phi=0$ above these values. While not realistic, they serve as extreme cases to evaluate the influence of a wavelength dependence on inactivation. Case 0 represents the scenario of wavelength-independent $\Phi$.

The values of $\Phi_{M S 2}(\lambda)$ and $\Phi_{\phi X 174}(\lambda)$ shown in Fig. 2 were then used to compute the direct endogenous inactivation rate constants $\left(k_{M S 2}^{\text {endo }}\right.$ and $\left.k_{\phi X 174}^{\text {endo }}\right)$ in an actual WSP under natural sunlight, according to eq. (3) (Mattle et al., 2015):
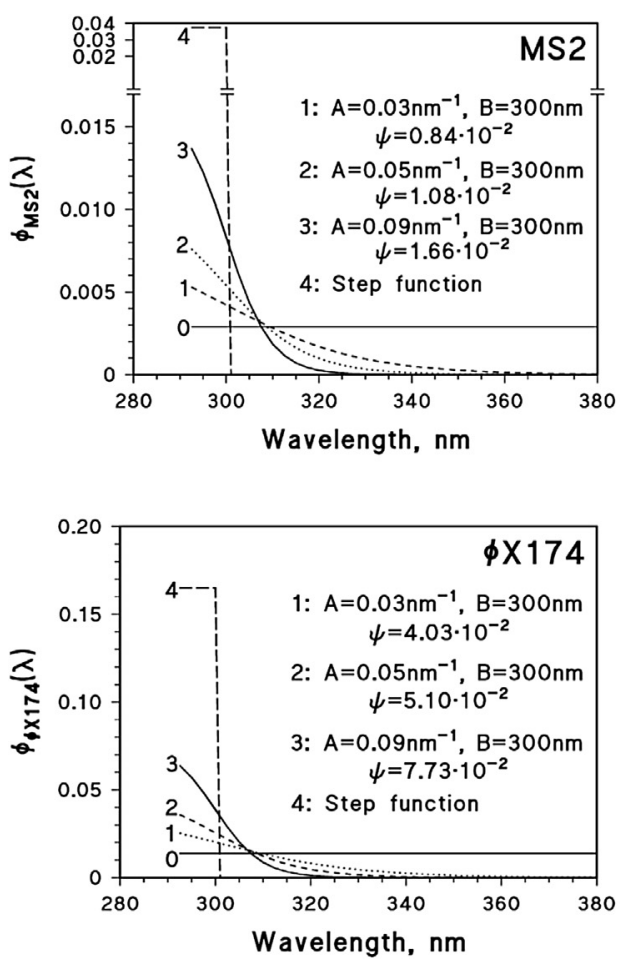

$k_{\text {endo }}^{\text {virus }}=\frac{1}{b} \int\left[\Phi_{\text {virus }}(\lambda) \frac{p^{\circ}(\lambda) \varepsilon_{\text {virus }}(\lambda)}{\alpha_{\text {solution }}(\lambda)}\left(1-10^{-\alpha_{\text {solution }}(\lambda) b}\right)\right] d \lambda$

where $p^{\circ}(\lambda)$ is the incident spectral photon flux density of sunlight (units of [photons $\mathrm{s}^{-1} \mathrm{~cm}^{-2} \mathrm{~nm}^{-1}$ ]), $\varepsilon_{\text {virus }}(\lambda)$ the virus absorption coefficient [ $\mathrm{mL}$ virus ${ }^{-1} \mathrm{~cm}^{-1}$ ] $\alpha_{\text {solution }}(\lambda)$ the specific absorbance of the solution (Absorbance/b, units of $\mathrm{cm}^{-1}$ ) and $b$ its optical path length $[\mathrm{cm}]$. Note that "virus" is a placeholder for "MS2"" or " $\phi X 174$ ". The input data $p^{\circ}(\lambda)$ and $\alpha_{\text {solution }}(\lambda)$ for eq. (3) (sunlight spectrum and WSP absorbance spectrum) are shown in Fig. 1.

Given that each wavelength trend shown in Fig. 2 yields a different inactivation in response to a given wavelength, it was of particular interest to consider a range of irradiance conditions. We therefore modeled $k_{M S 2}^{\text {endo }}$ and $k_{\phi X 174}^{\text {endo }}$ at different water depths, because the WSP preferentially absorbs light at lower wavelengths (Fig. 1), such that the relative contribution of UVB to the overall irradiance spectrum decreases with depth. The contribution of exogenous inactivation was not considered because exogenous processes are not affected by the endogenous photoinactivation quantum yield.

The results concerning the modeling of $k_{M S 2}^{\text {endo }}$ and $k_{\phi X 174}^{\text {endo }} v s$. water depth are shown in Fig. 3, where selected cases are reported (cases 0,3 , and 4). Cases 1, 2, 5, 6, and 7 were located between cases 0 and 3 , featuring very small differences compared to the constantwavelength scenario, while case 8 was very similar to 3 . Therefore, approximately the same inactivation rate constants are computed, independent of whether a constant or a wavelength-dependent quantum yield is used. The sole exception is the step function (case 4), for which greater deviations from case 0 could be observed. Interestingly, a threefold deviation is already evident at zero depth, and therefore cannot be attributed to different responses to changes in the irradiance spectrum with depth. Instead, the difference between case 0 and case 4 is likely an experimental
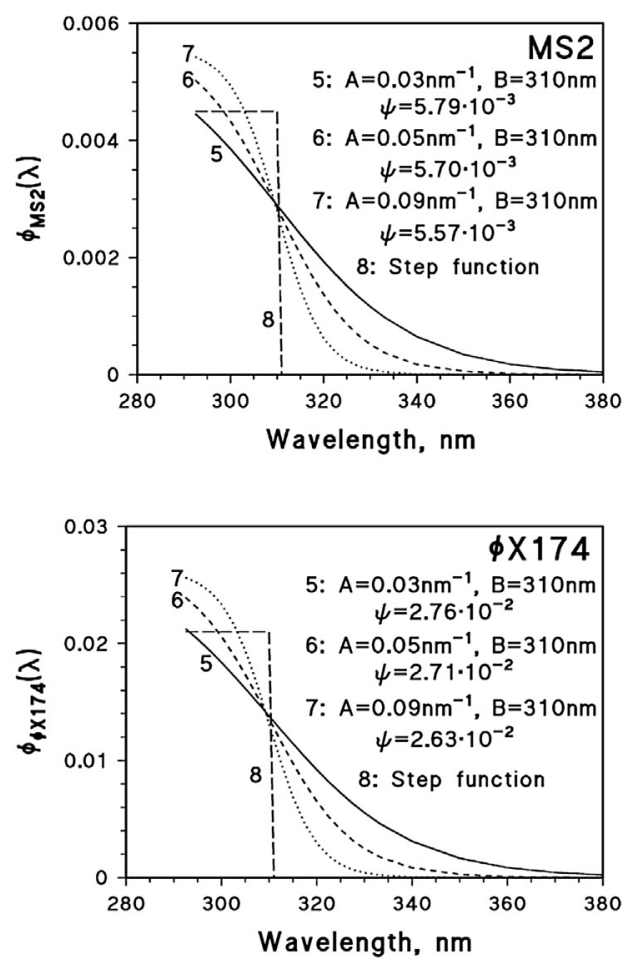

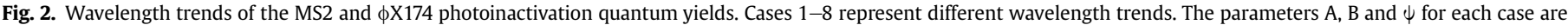

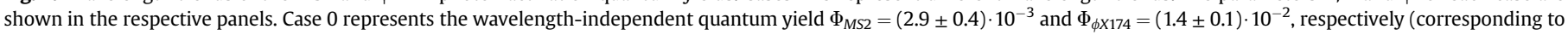
eq. (2) with $A=0$; see also Table 1 ). Note the Y-axis break in the left MS2 panel. 

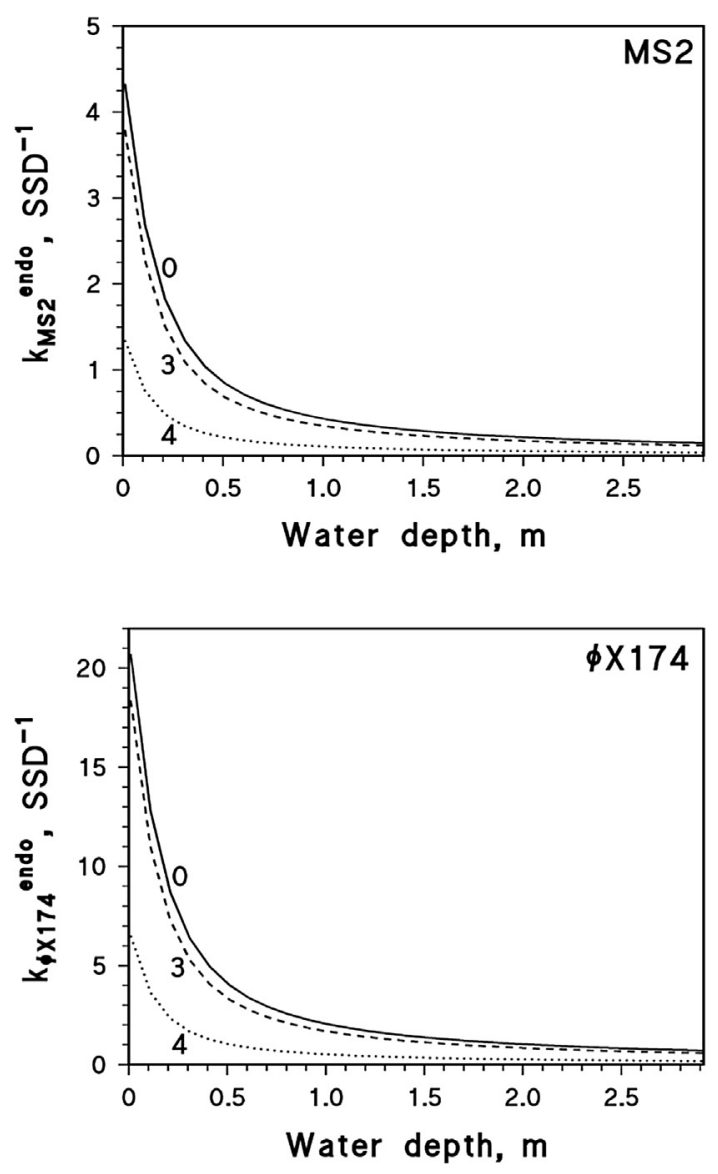

Fig. 3. First-order rate constants for the endogenous photoinactivation as a function of WSP depth. Lines represent rate constants obtained for cases 0 ( $\Phi_{\text {virus }}$ independent of wavelength), 3 and 4 ( $\Phi_{\text {virus }}(\lambda)$, see Fig. 2$)$. Water chemistry parameters are those of Table 1 and the water absorption spectrum is reported in Fig. 1.

artifact associated with differences in the spectral features of the solar simulator used to obtain experimental $k_{\text {virus }}^{\text {endo }}$ values, and of the solar spectrum used in APEX (see Fig. 1). These spectral differences are overstressed in case 4 compared to the other scenarios.

To summarize, in most of the tested cases the kinetics of direct virus photoinactivation would not be much different under the scenarios of constant $\Phi_{\text {virus }}$ or wavelength-variable $\Phi_{\text {virus }}(\lambda)$. With the exception of case 4 , which is an unlikely wavelength trend, the use of constant quantum yields obtained under simulated sunlight leads to only a small $(\leq 25 \%)$ overestimation of the endogenous photoinactivation kinetics. The main uncertainty associated with the use of constant $\Phi_{\text {virus }}$ rather than wavelength-variable $\Phi_{\text {virus }}(\lambda)$ is of experimental, rather than conceptual nature, and concerns the extent by which laboratory irradiation is representative of the outdoor environment.

\subsection{Photoinactivation as a function of WSP depth: contribution of different inactivation processes}

After the successful evaluation and calibration of the model, the latter was applied to outdoor sunlight (see Fig. 1 for the sunlight $p^{\circ}(\lambda)$ used for modeling). $k_{\text {virus }}^{0}$ as well as the relative role of the various photoreactions were assessed as a function of water depth $d$, with $d$ values that are relevant to WSPs $(0-3 \mathrm{~m})$. The model results are reported in Fig. 4 for both MS2 and $\phi X 174$, under conditions that are relevant to fair weather mid-July at mid latitude. It
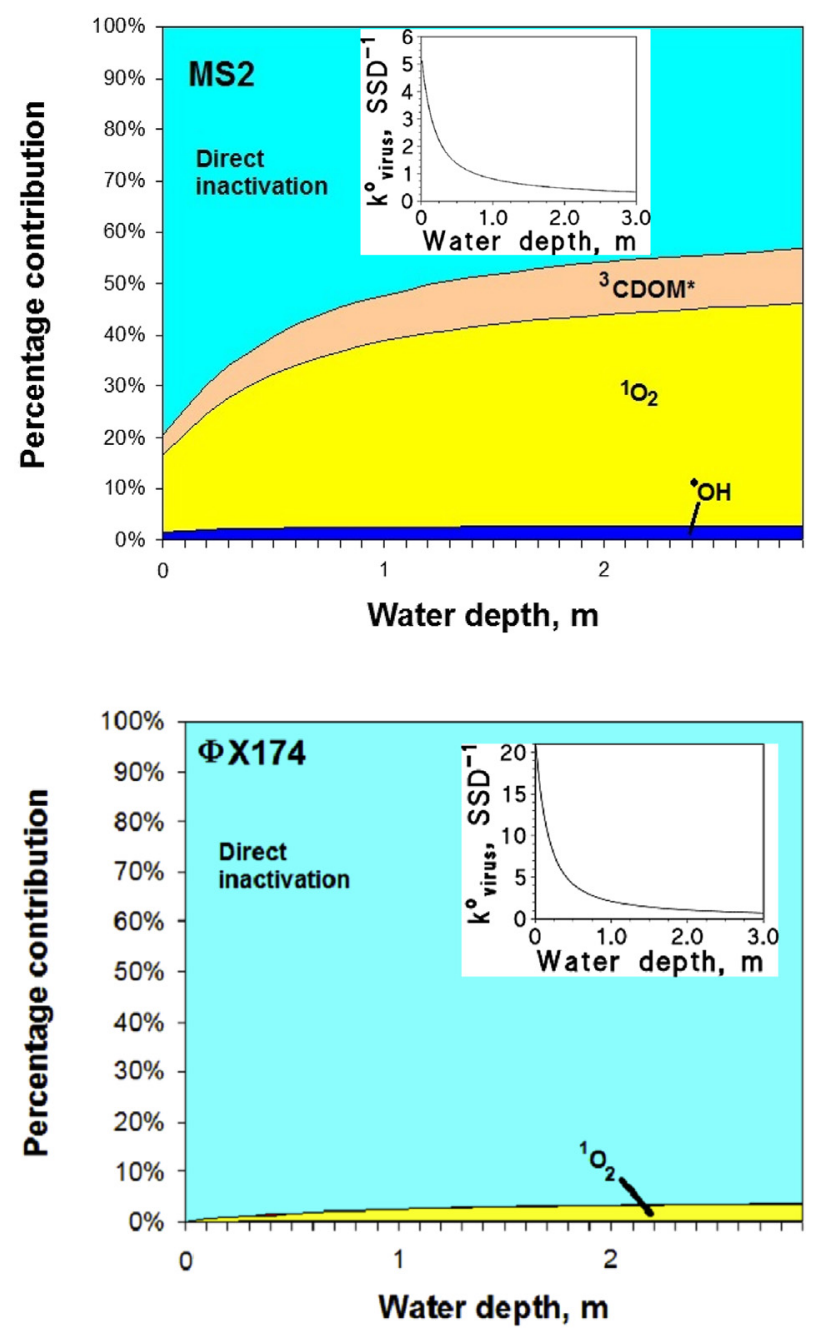

Fig. 4. Modeled contributions of the different photoinactivation processes of MS2 and $\phi X 174$ under summertime sunlight, as a function of WSP water depth. Water chemistry parameters used for modeling are reported in Table 1 . The inserts in both panels show the respective $k_{\text {virus }}^{o}$ values as a function of the water depth.

is important to note that APEX gives average values for a mixed water column of given depth. Therefore, the percentage contribution of, say, ${ }^{1} \mathrm{O}_{2}$ for the depth $d=2 \mathrm{~m}$ represents the average role of ${ }^{1} \mathrm{O}_{2}$ in a well mixed $2-\mathrm{m}$ water column and not the point value at $2 \mathrm{~m}$ depth. Therefore, Fig. 4 is not a depth profile of a single WSP but it rather compares the column-averaged behavior of WSPs with different depths. In thermally stratified WSPs, the photoinactivation kinetics would be slower than in mixed ones.

From the inserts in Fig. 4 it is evident that both viruses are rapidly inactivated in shallow ponds, but photoinactivation becomes less efficient for deeper water columns. The decrease of $k_{v i r u s}^{o}$ with increasing depth is due to the fact that only shallow ponds are thoroughly illuminated by sunlight. In deeper ponds, the elevated photoreactivity of the surface water layer is compensated for by the low photoreactivity of the poorly illuminated deep water, and the compensation becomes more important as the depth increases.

Interestingly, in shallow ponds (depth $<20 \mathrm{~cm}$ ), $k_{\phi X 174}^{o} \approx 4 k_{M S 2}^{o}$, whereas in deeper WSPs this relationship approaches $k_{\phi X 174}^{0} \approx 2 k_{M S 2}^{o}$. This trend can be rationalized by comparing the photoinactivation parameters of the two viruses listed in Table 1: $\phi X 174$ has an approximately five-fold larger inactivation quantum yield than MS2 and in addition the photon flux absorbed by $\phi \mathrm{X} 174$ 
( $P_{a}^{\text {virus }}$ in eq. (1a)) is slightly larger than that of MS2 (Mattle et al., 2015; see Appendix A for virus absorbance spectra). Overall, endogenous inactivation is thus more efficient for $\phi X 174$ than for MS2, which results in faster overall photoinactivation in shallow WSPs. However, endogenous inactivation is triggered by light in the UVB region that is considerably attenuated in WSP water. Therefore, as WSP depth increases, the relative importance of endogenous inactivation decreases, whereas that of exogenous inactivation, which can also be initiated by light of higher wavelengths, increases. Compared to $\phi X 174$, MS2 is more susceptible to exogenous inactivation by all reactive species studied (Table 1), which accounts for the decreasing ratio of $k_{\phi X 174}^{o}\left(k_{M S 2}^{o}\right)^{-1}$ as WSPs get deeper.

Among the reactive species studied, the greatest contribution to exogenous inactivation of both viruses can be attributed to ${ }^{1} \mathrm{O}_{2}$. This is consistent with previous findings in a different WSP matrix, where ${ }^{1} \mathrm{O}_{2}$ was also identified as the main contributor to exogenous inactivation of MS2 (Kohn and Nelson, 2007). For water depths of 2-3 m, exogenous inactivation by ${ }^{1} \mathrm{O}_{2}$ gives a comparable contribution to $k_{M S 2}^{o}$ as endogenous inactivation. Among the minor photoreactions, ${ }^{3} \mathrm{CDOM}^{*}$ and ${ }^{\circ} \mathrm{OH}$ have comparable importance at low depth but the relative role of ${ }^{3} \mathrm{CDOM}^{*}$ increases in deeper water. The reason is that ${ }^{\circ} \mathrm{OH}$ is produced by the photolysis of nitrate ( $<5 \%$ of the total) and most notably of nitrite and CDOM, while ${ }^{3} \mathrm{CDOM}^{*}$ (as well as ${ }^{1} \mathrm{O}_{2}$ ) is produced by irradiated $\mathrm{CDOM}$ alone. The photochemistry of nitrite (which absorbs mainly in the UVA) and nitrate (mainly absorbing in the UVB) is more attenuated in deep water than that of CDOM, which explains why the relative role of ${ }^{3} \mathrm{CDOM}^{*}$ (and of ${ }^{1} \mathrm{O}_{2}$ ) increases with depth compared to ${ }^{\circ} \mathrm{OH}$.

In contrast to MS2, the photoinactivation of $\phi \times 174$ is dominated by endogenous inactivation at all the modeled depths. Nevertheless, the relative importance of ${ }^{1} \mathrm{O}_{2}$ also increases with depth for this case, from $<1 \%$ to about $4 \%$ of total photoinactivation.

\subsection{Photoinactivation as a function of season}

The seasonal trend of the photoinactivation kinetics was determined by using the APEX_season function of the APEX software. This function uses data of the solar spectrum at mid latitude, adjusted to the different months of the year, to obtain the seasonal trend of photochemically relevant parameters (Avetta et al., 2014). The present calculation is based on WSP water with the chemical composition reported in Table 1 , and a water column depth $d=2 \mathrm{~m}$.

Fig. 5a reports the values of $k_{M S 2}^{o}$ and $k_{\phi X 174}^{o}$ in different months, showing an expected summer maximum and a winter minimum for both viruses. Photoinactivation of MS2 in summer could be about ten times faster than in winter, whereas the seasonal differences would be even more pronounced (over 20-fold) for $\phi X 174$. These differences can mainly be attributed to the low irradiance in the UVB region during winter (Frank and Klöpffer, 1988). The low UVB irradiance leads to a reduced rate of endogenous inactivation, and hence to a decrease in the overall inactivation in the winter. This effect is particularly pronounced for $\phi X 174$, which is dominated by endogenous inactivation (Fig. 4).

Seasonal variations are less pronounced for MS2, because the decrease in endogenous inactivation is partly buffered by exogenous inactivation induced by higher wavelength light that is less affected by season (Fig. 5b). As a result, we find a slightly more important role of indirect MS2 inactivation played by ${ }^{1} \mathrm{O}_{2}$ in winter (though differences in ${ }^{1} \mathrm{O}_{2}$ contributions are lower than the calculation uncertainties). The inactivation fraction accounted for by ${ }^{1} \mathrm{O}_{2}$ varies from $\sim 40 \%$ in summer to $\sim 60 \%$ in winter (Fig. $5 \mathrm{~b}$ ).

In addition to differences in the solar irradiance spectrum (also affected by elevation) and possible weather-related variability throughout the year (not considered here, but that could increase
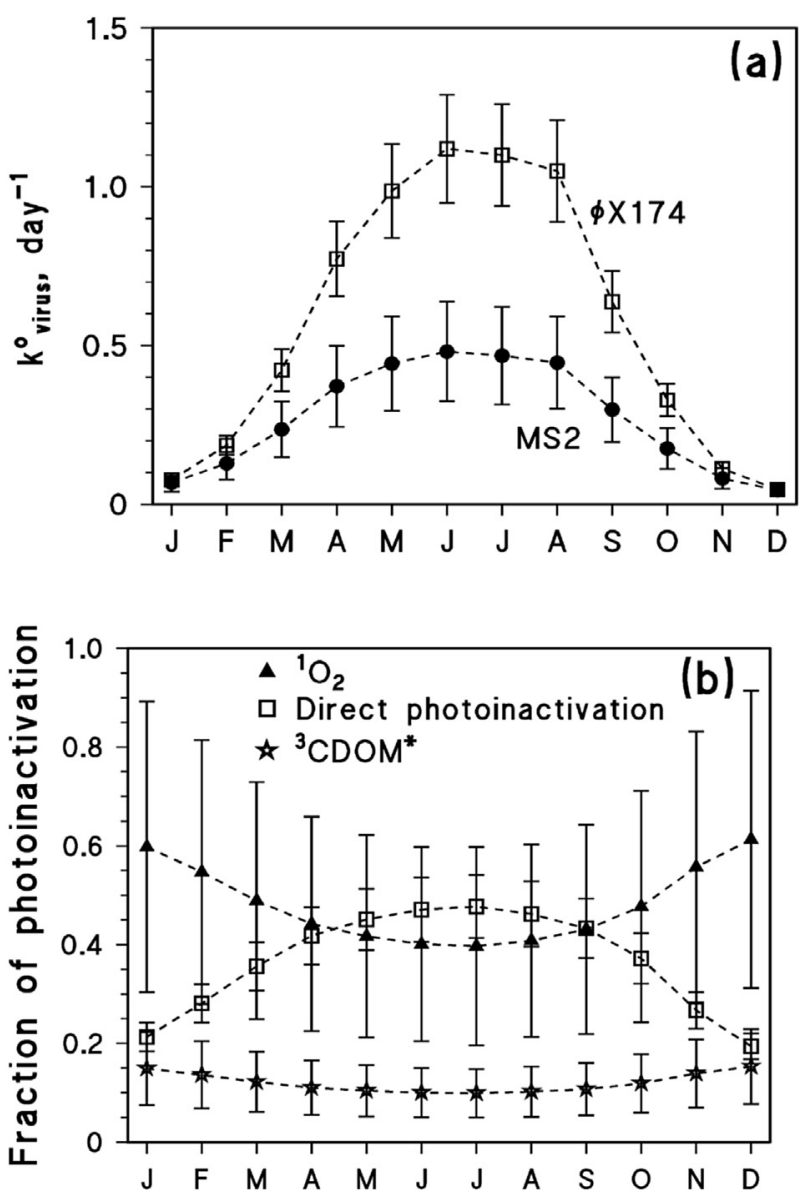

Fig. 5. Inactivation as a function of season. (a) Pseudo-first order rate constants for the photoinactivation of MS2 and $\phi X 174$, at mid latitude in the different months of the year. The time unit is days of the relevant month. (b) Fraction of MS2 photoinactivation accounted for by the main photoinduced processes (endogenous photoinactivation and reaction with ${ }^{1} \mathrm{O}_{2}$ and ${ }^{3} \mathrm{CDOM}^{*}$ ) in the different months of the year. Water chemistry parameters used for modeling are reported in Table 1 , and it was assumed $d=2 \mathrm{~m}$. The error bounds represent $95 \%$ confidence intervals.

the relative differences between summer and winter in many midlatitude locations), temperature fluctuations will also impact the rate of photoinactivation. Specifically, it has been shown that temperature in the environmentally relevant range (up to $40{ }^{\circ} \mathrm{C}$ ) increases the rate of exogenous photoinactivation (Carratalà et al., n.d.; Romero et al., 2011), but not endogenous photoinactivation (Romero et al., 2011). The effect of temperature was not included in the model. We therefore assume that the model slightly overpredicts $k_{M S 2}^{o}$ in the winter, and under-predicts $k_{M S 2}^{o}$ in the summer. In contrast, $k_{\phi X 174}^{o}$ should not be strongly affected by temperature, due to its low sensitivity to indirect photoinactivation.

\subsection{Photoinactivation as a function of latitude}

On the basis of the solar spectrum at the ground at different latitudes, one can compute the expected latitude trend of the photoinactivation rate constants. Fig. 6 reports the modeled photoinactivation rate constants for both MS2 and $\phi X 174$ as a function of latitude, taking into account the spring equinox in the northern hemisphere. As expected, photoinactivation would become progressively less effective when moving towards higher latitudes. Interestingly, $\phi X 174$ would be inactivated faster than MS2 below $60^{\circ} \mathrm{N}$, and more slowly at higher latitudes. The reason is that $\phi \mathrm{X} 174$ is mainly inactivated endogenously, which requires the action of 


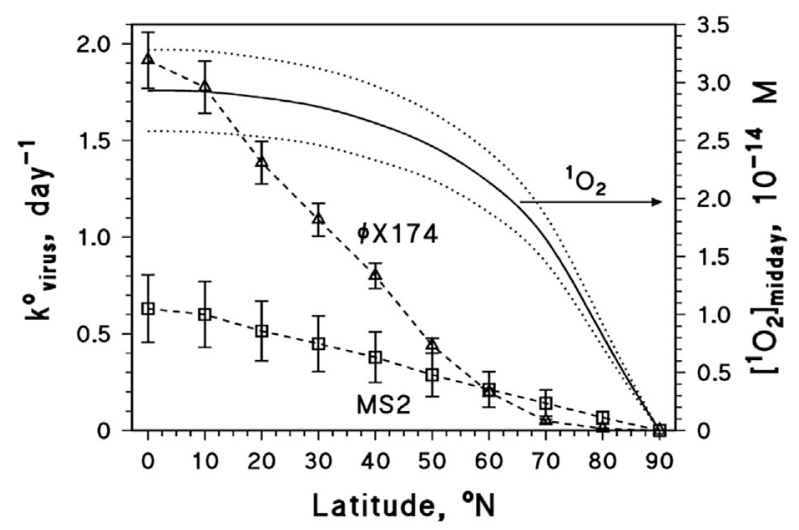

Fig. 6. Inactivation as a function of latitude. Inactivation rate constants were computed for the northern hemisphere, for fair-weather days at the spring equinox. The time unit is days equivalent to the spring equinox at the given latitude. Water chemistry parameters used for modeling are reported in Table 1 , and it was assumed $d=2 \mathrm{~m}$. The error bounds represent $95 \%$ confidence intervals. The graph also reports the steadystate ${ }^{1} \mathrm{O}_{2}$ concentration (assessed for midday sunlight at the relevant latitude), together with the $95 \%$ confidence bands (dotted).

UVB radiation, and the UVB is the region of the solar spectrum undergoing the sharpest decrease in irradiance with increasing latitude. In contrast, MS2 also undergoes reaction with ${ }^{1} \mathrm{O}_{2}$ that requires $U V-$ vis activation of CDOM and is less latitude-sensitive. For comparison, Fig. 6 also reports the latitude trend of the steady-state ${ }^{1} \mathrm{O}_{2}$ concentration at midday, which is less marked compared to the photoinactivation kinetics of MS2 and most notably $\phi X 174$.

Moreover, one should consider for practical applications that virus photoinactivation at higher latitudes becomes rapidly less effective compared to low latitudes. For example, in order to achieve a $99 \%$ ( $2 \mathrm{log} ; C_{\text {virus }} / C_{\text {virus, } 0}=0.01$ in eq. (1b)) inactivation of MS2 in a WSP of $2 \mathrm{~m}$ depth, one would need a hydraulic residence time (HRT) of only 7.3 days at $0^{\circ}$, approximately 14 days at $45^{\circ}$, and of $>20$ days at $60^{\circ}$. In the case of $\phi X 174$, the HRTs would correspond to 2.4 days, 8 days, and $>20$ days, respectively. This illustrates that at high latitudes, very large pond volumes or low flow rates are needed. While WSPs with total HRTs $>20$ days exist, shorter HRTs are more common (Verbyla and Mihelcic, 2014). To reduce the HRT and pond size requirements at high latitudes, it is thus a good strategy to reduce the pond depth, as a reduction in depth exponentially increases $k_{\text {virus }}^{0}$ (Fig. 4) but only proportionally increases the HRT. An additional advantage of shallow ponds is that they allow sunlight exposure of viruses even if the pond is not fully mixed.

\subsection{Role of WSP solution constituents}

Up to now, most of the photochemical modeling was based on the water chemistry data reported in Table 1 and referred to a WSP sample from Vuiteboeuf, Switzerland (Mattle et al., 2015). The effects of variations in depth and sunlight irradiance (due to latitude or season) were assessed, but water chemistry was not modified. Therefore, further modeling was carried out with APEX by varying water chemical parameters of interest for the photoinactivation of MS2 and $\phi X 174$.

Because photoinactivation largely involves endogenous inactivation and indirect reactions with ${ }^{1} \mathrm{O}_{2}$ and ${ }^{3} \mathrm{CDOM}^{*}$ (Fig. 4), organic matter and depth would be the most important water variables. Indeed, organic matter (measured as dissolved organic carbon, $\mathrm{DOC}$ ) is the main photochemical source of ${ }^{1} \mathrm{O}_{2}$ and ${ }^{3} \mathrm{CDOM}^{*}$ and it is also the main sunlight absorber in WSP water. By absorbing sunlight, organic matter would inhibit the endogenous photoinactivation of viruses in deep waters. In the model, a simple Lambert-Beer proportionality between water absorbance and DOC was assumed (Bodrato and Vione, 2014), taking Vuiteboeuf WSP water as reference (its absorption spectrum is reported in Fig. 1 and it corresponds to $14.4 \mathrm{mg} \mathrm{C} \mathrm{L}^{-1} \mathrm{DOC}$ ). The other water parameters of photochemical significance (nitrate, nitrite, carbonate, bicarbonate) were initially varied but, given the negligible contribution of carbonate and hydroxyl radicals to MS2 and $\phi X 174$ inactivation, their variations would not significantly influence the model results. Therefore, they were kept at the values reported in Table 1.

Fig. 7 illustrates how inactivation is affected by depth $d$ and DOC. As discussed above (Fig. 4), both $k_{M S 2}^{o}$ and $k_{\phi X 174}^{0}$ rapidly decrease with depth due to the effects of increasing screening of UVB light. The decrease of $k_{M S 2}^{o}$ and $k_{\phi X 174}^{o}$ with increasing DOC is more complex to rationalize, as it is the result of different and opposite trends. On the one side, increasing DOC and water absorbance inhibits the endogenous inactivation. On the other hand, the relative importance of reactions with ${ }^{1} \mathrm{O}_{2}$ and ${ }^{3} \mathrm{CDOM}^{*}$ would increase with DOC, because organic matter is a major source of both ${ }^{1} \mathrm{O}_{2}$ and ${ }^{3} \mathrm{CDOM}^{*}$. Of the two opposite effects, the inhibition of endogenous inactivation is more important and causes the observed decrease in photoinactivation. $k_{M S 2}^{o}$ varies from $\sim 4.5 \mathrm{SSD}^{-1}$ at low DOC and low
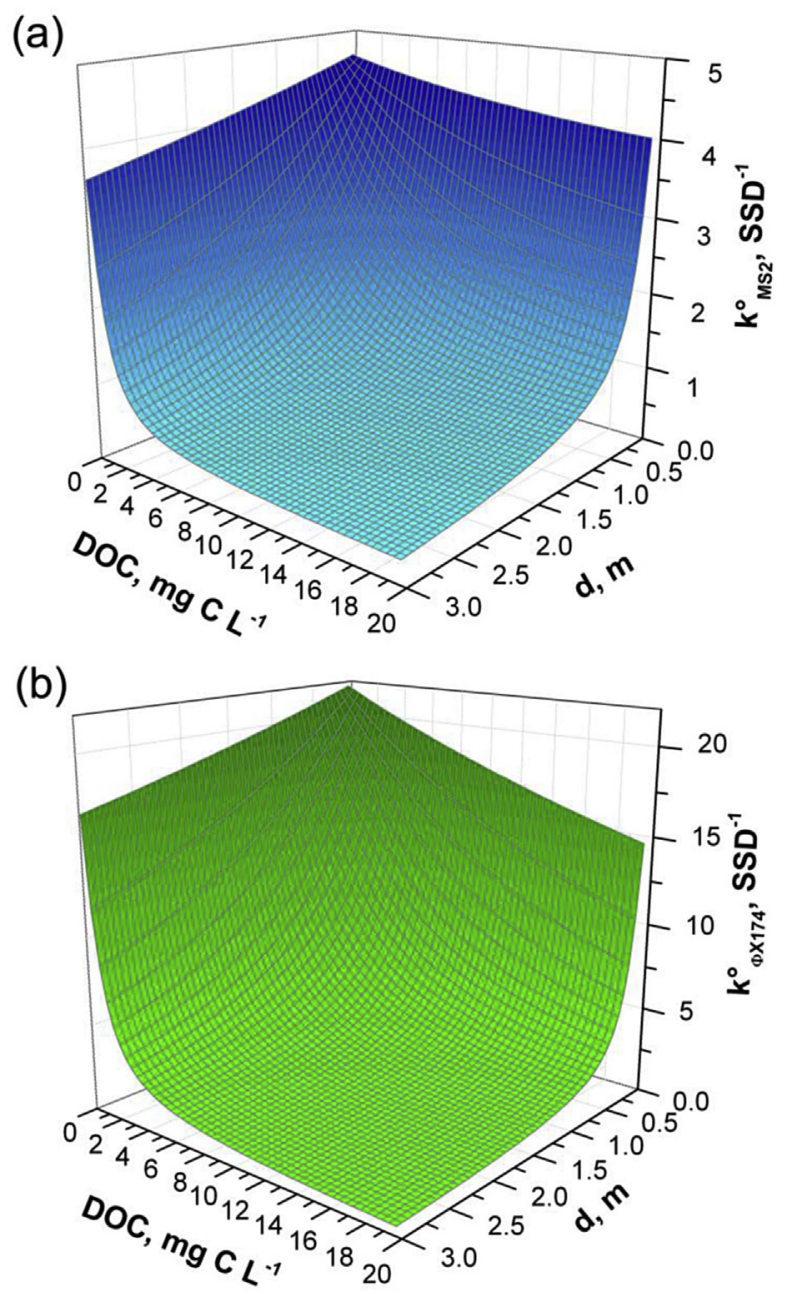

Fig. 7. Effect of depth and DOC on inactivation. Photoinactivation rate constant of (a) MS2, $k_{M S 2}^{o}$, and (b) $\phi X 174, k_{\phi X 174}^{o}$, as a function of water depth $d$ and DOC. Other water parameters of photochemical significance are given in Table 1. Irradiation conditions correspond to fair-weather 15 July at mid latitude. 
depth, to $\sim 0.3 \mathrm{SSD}^{-1}$ for DOC $=20 \mathrm{mg} \mathrm{C} \mathrm{L}^{-1}$ and $d=3 \mathrm{~m}$. The values of $k^{o}{ }^{\prime}$ vary from $\sim 22 \mathrm{SSD}^{-1}$ at low DOC and low depth, to $\sim 0.5 \mathrm{SSD}^{-1}$ for DOC $=20 \mathrm{mg} \mathrm{C} \mathrm{L}^{-1}$ and $d=3 \mathrm{~m}$. The $k_{\phi X 174}^{o}$ decrease is more marked compared to MS2, for which the endogenous photoinactivation would be partially replaced by exogenous inactivation by ${ }^{1} \mathrm{O}_{2}$ (and, to a lesser extent, by ${ }^{3} \mathrm{CDOM}^{*}$ ) at elevated depth and DOC. In contrast, in the case of $\phi X 174$, the reactions with ${ }^{1} \mathrm{O}_{2}$ and ${ }^{3} \mathrm{CDOM}^{*}$ would never account for more than 5 and $0.2 \%$, respectively, of the total photoinactivation.

These calculations confirm the intuitive notion that in order to achieve significant photoinactivation, WSP depth should decrease with increasing DOC. In addition, however, the DOC content may also influence the type of damage incurred by the virus, and hence the inactivation mechanism. In earlier studies, we have found that endogenous inactivation by light in the UVC range mainly causes genome damage, which inhibits virus replication. In contrast, ${ }^{1} \mathrm{O}_{2}$ additionally damages viral proteins involved in earlier steps of the virus infection process, namely the attachment to host cells and the internalization of the viral genome (Bosshard et al., 2013; Wigginton et al., 2012). For some viruses, in particular ones with a double-stranded DNA genome (e.g., adenovirus), genome damage can be repaired by the host cell. In contrast, no repair mechanism is known for damaged viral proteins. These results suggest that while overall solar disinfection in WSPs with a high DOC is slow due to the limited contribution of endogenous inactivation, the disinfection achieved is more permanent due to the significant contribution of ${ }^{1} \mathrm{O}_{2}$.

\subsection{Virus photoinactivation in natural waters}

The modeling carried out thus far was specific to WSP water. In particular, APEX used the formation quantum yields of ${ }^{\circ} \mathrm{OH},{ }^{1} \mathrm{O}_{2}$, $\mathrm{CO}_{3}{ }^{-\cdot}$ and ${ }^{3} \mathrm{CDOM}^{*}$ by irradiated CDOM, measured in the Vuiteboeuf WSP water, as well as the corresponding values for the reactivity of ${ }^{\cdot} \mathrm{OH}$ and $\mathrm{CO}_{3}{ }^{-\cdot}$ with WSP organic matter (Mattle et al., 2015). To predict the kinetics of virus photoinactivation in the natural environment, APEX utilized kinetic parameters for the photoproduction of reactive species measured in natural surface waters (Al Housari et al., 2010; Bodrato and Vione, 2014; Loiselle et al., 2012). Furthermore, we assumed here that the photoreactivity parameters of viruses are intrinsic properties that do not depend on the matrix in which they were determined. Therefore the photoreactivity parameters of both viruses (photoinactivation quantum yields and reaction rate constants with ${ }^{\circ} \mathrm{OH}, \mathrm{CO}_{3}{ }^{-\cdot},{ }^{1} \mathrm{O}_{2}$ and ${ }^{3} \mathrm{CDOM}^{*}$ ) remained those reported in Table 1 .

Fig. 8a and b report the modeled $k_{M S 2}^{o}$ and $k_{\phi X 174}^{o}$ for surfacewater conditions, as a function of depth and DOC. Other water parameters were $0.1 \mathrm{mM}$ nitrate, $1 \mu \mathrm{M}$ nitrite (the nitrite/nitrate ratio is often lower in surface compared to WSP water; Vione, 2014), $1 \mathrm{mM}$ bicarbonate and $10 \mu \mathrm{M}$ carbonate (corresponding to $\mathrm{pH} \sim 8.3$ ). The photoinactivation rate constant of MS2 varies from $k_{M S 2}^{o} \sim 11 \mathrm{SSD}^{-1}$ at low depth and low DOC to $k_{M S 2}^{o} \sim 0.1 \mathrm{SSD}^{-1}$ for $d=10 \mathrm{~m}$ and $\mathrm{DOC}=10 \mathrm{mg} \mathrm{C} \mathrm{L} \mathrm{L}^{-1}$. The rate constant $k_{\phi X 174}^{0}$ varies from $\sim 25 \mathrm{SSD}^{-1}$ at low depth and DOC to $\sim 0.3 \mathrm{SSD}^{-1}$ for $d=10 \mathrm{~m}$ and $\mathrm{DOC}=10 \mathrm{mg} \mathrm{C} \mathrm{L}^{-1}$. Under comparable water and irradiation conditions, $k_{\phi X 174}^{o}$ is thus always larger than $k_{M S 2}^{o}$.

In natural waters, solar disinfection can remain an important contributor to overall virus inactivation, even if the water column is deep. In waters with a low DOC, such as seawater or oligotrophic surface waters ( 1 $\mathrm{mg} \mathrm{C} \mathrm{L}^{-1}$ DOC; Thurman, 2012), a 99\% inactivation of $\phi X 174$ could be achieved in a week in a water column as deep as $40 \mathrm{~m}$. In eutrophic freshwater with a DOC content of $4 \mathrm{mg} /$ $\mathrm{L}$, to achieve the same inactivation in a week one would need much shallower water (11 m depth). For the more photostable MS2, the corresponding water depths needed for $99 \%$ inactivation in a week (a)

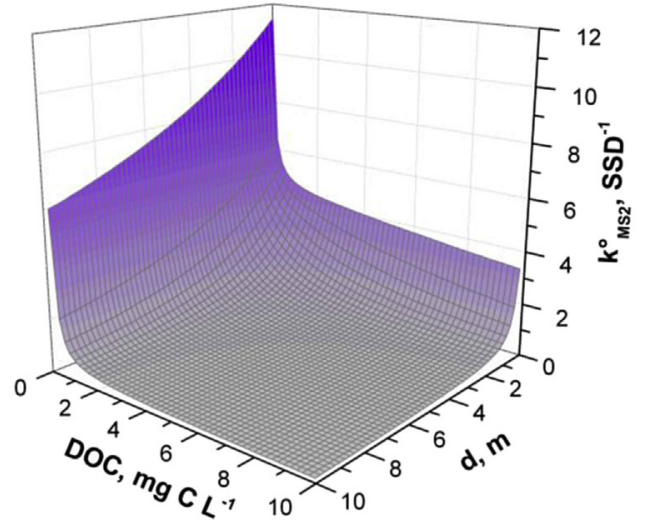

(b)

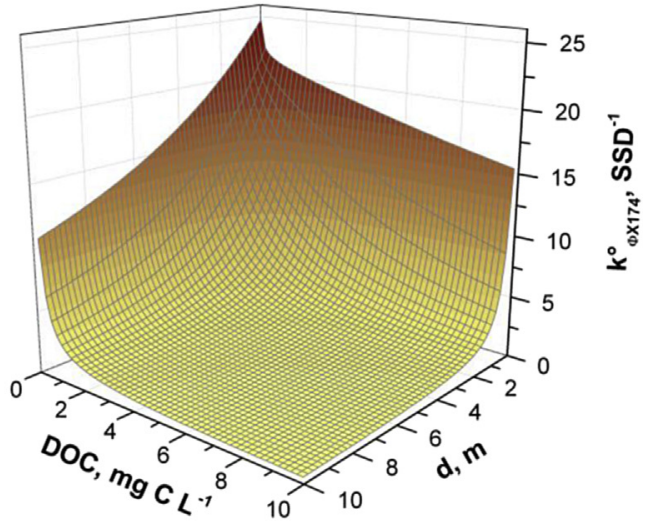

(c)

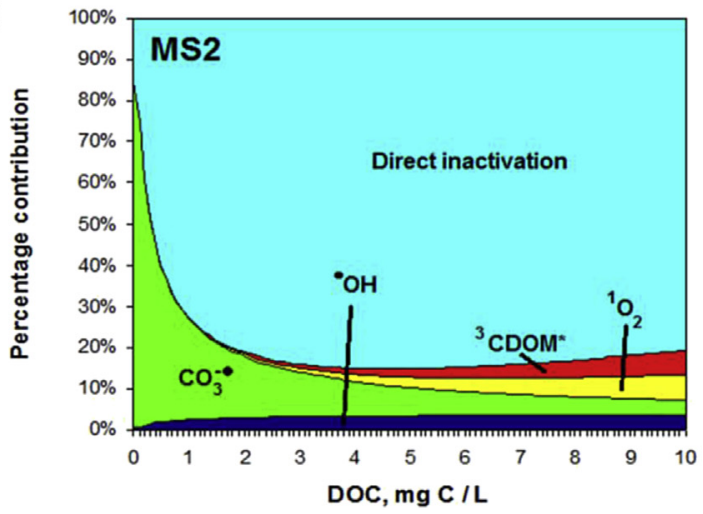

Fig. 8. Inactivation in natural surface water. (a) Photoinactivation rate constant of MS2, $k_{M S 2}^{o}$, (b) and $\phi X 174, k_{\varphi X 174}^{0}$, in natural water. (c) Contribution of different processes on MS2 photoinactivation in natural water, as a function of DOC. Other water parameters of photochemical significance are $0.1 \mathrm{mM}$ nitrate, $1 \mu \mathrm{M}$ nitrite, $1 \mathrm{mM}$ bicarbonate, $10 \mu \mathrm{M}$ carbonate, and $5 \mathrm{~m}$ depth. Irradiation conditions correspond to fair-weather 15 July at mid latitude.

would be 9 and $2.5 \mathrm{~m}$, respectively.

In the case of $\phi \times 174$ the direct photolysis would be the prevailing photoinactivation process in natural waters, as was the case for WSP water. For the inactivation of MS2, there are two interesting differences compared to the WSP scenario, namely the large contribution of $\mathrm{CO}_{3}{ }^{-\cdot}$ in low-DOC water, and the comparatively minor role of ${ }^{1} \mathrm{O}_{2}$ at all DOC concentrations considered (Fig. 8c). The importance of $\mathrm{CO}_{3}{ }^{-\cdot}$ can be explained by taking into account the following considerations: first, organic matter is the main sink of $\mathrm{CO}_{3}{ }^{-\cdot}$ in both WSP and natural waters. However, compared to the more aged and photobleached autochthonous organic matter of 
natural waters, the wastewater-derived organic matter contains more electron-rich moieties which can react with $\mathrm{CO}_{3}{ }^{-}$. Indeed, the reaction rate constant of $\mathrm{CO}_{3}{ }^{-\cdot}$ with WSP water organic matter was much higher than that of surface-water organic matter (Canonica et al., 2005; Mattle et al., 2015). As a consequence, at an equal DOC content, the steady-state concentration of $\mathrm{CO}_{3}{ }^{-\cdot}$ will be lower in a WSP than in natural water.

Second, the role of $\mathrm{CO}_{3}{ }^{-\cdot}$ is particularly important in low-DOC waters (Fig. 8c). In higher DOC water, $\mathrm{CO}_{3}{ }^{-\cdot}$ is largely quenched by organic matter. In addition, organic matter acts as a ${ }^{\circ} \mathrm{OH}$ sink and thus inhibits the generation of $\mathrm{CO}_{3}{ }^{-\cdot}$ via the ${ }^{\circ} \mathrm{OH}$-mediated oxidation of carbonate and bicarbonate (Canonica et al., 2005). Low DOC concentrations conducive to important $\mathrm{CO}_{3}{ }^{-\cdot}$ concentrations are common of natural waters, but are unlikely to be encountered in wastewaters.

The secondary role of ${ }^{1} \mathrm{O}_{2}$ in natural water can be explained by the lower formation quantum yield of ${ }^{1} \mathrm{O}_{2}$ compared to WSP water (Mattle et al., 2015). This may be due to the relatively recent formation of WSP CDOM and its limited history of exposure to sunlight. Indeed, there is evidence that sunlight irradiation decreases the ability of CDOM to photogenerate reactive species such as ${ }^{1} \mathrm{O}_{2}$ (De Laurentiis et al., 2013; Loiselle et al., 2012).

\subsection{Comparison of computed and measured inactivation data}

The model discussed herein was calibrated using experimental laboratory results from our group. However, the ultimate goal is to use this model to predict inactivation in the field. To test the feasibility of this goal, we searched the literature for field measurements of phage inactivation, and compared these data with inactivation rates computed by our model. We identified two studies which reported the necessary information on water quality parameters, as well as on the season and latitude at which the study was conducted (Boehm et al., 2009; Silverman et al., 2015). In both studies, the authors considered wastewater-impacted waters. Our model predictions were therefore carried out using the model calibrated to Vuiteboeuf WSP water.

In the first study, the photoinactivation of MS2 and F+RNA coliphages under natural sunlight was assessed in the Discovery Bay wetland, California $\left(\sim 38^{\circ} \mathrm{N}\right.$ latitude, $20 \mathrm{~cm}$ water depth, $8 \mathrm{mg} \mathrm{C} \mathrm{L}$ DOC) (Silverman et al., 2015). In the case of MS2 around spring equinox conditions, the wetland $k_{M S 2}^{o}$ values (accounted for by direct endogenous inactivation and reaction with ${ }^{1} \mathrm{O}_{2}$ ) was measured to be around $2.5 \pm 0.5 \mathrm{day}^{-1}$. Our model prediction for the given latitude and water conditions is $1.95 \pm 0.46 \mathrm{day}^{-1}$. The prediction is thus in good agreement with the reported data. The difference could be accounted for by the fact that irradiated CDOM in the Discovery Bay wetland produces ${ }^{1} \mathrm{O}_{2}$ to a higher extent compared to Vuiteboeuf CDOM (Silverman et al., 2015). Additionally, the CDOM present in Discovery Bay may associate more readily with MS2 than the Vuiteboeuf CDOM. As previous studies have shown, MS2-CDOM associations enhance inactivation, as the virus is in close vicinity to the source of ${ }^{1} \mathrm{O}_{2}$ and hence is exposed to greater ${ }^{1} \mathrm{O}_{2}$ concentrations than those measured in the bulk solution (Kohn et al., 2007). Finally, other factors not explicitly considered herein, such as the temperature dependence of exogenous photoinactivation or uncertainties in the HRT of the wetland may contribute to the difference between model and measurement.

In the second study, photoinactivation rate constants of somatic phages were measured in Avalon Bay, California (late August, $\sim 33^{\circ} \mathrm{N}$ latitude, $\sim 15 \mathrm{~cm}$ water depth, $7 \mathrm{mg} \mathrm{C} \mathrm{L}^{-1}$ DOC) (Boehm et al., 2009). These authors derived a maximal photoinactivation rate of $28 \mathrm{day}^{-1}$. We compared this measurement with our model prediction for $\phi X 174$, which is a somatic phage, and obtained a predicted rate constant $k_{\phi X 174}^{o}$ of $32 \pm 2$ day $^{-1}$. This is a surprisingly good correspondence, especially considering that the phages in the field study were not identical to those considered in the model. Other differences between the model prediction and the field system include the high ionic strength and the presence of halide species in the marine environment. These factors have previously been found to enhance the photoinactivation of viruses (Sinton et al., 2002). However, they were not considered herein as APEX was not developed and validated for water with high ionic strength and high concentrations values of chloride and bromide, except for the fact that it can account for the major role of bromide as ${ }^{\circ} \mathrm{OH}$ scavenger in saltwater (Bodrato and Vione, 2014).

Overall, the model predictions using APEX are encouraging in that they yield results similar to those obtained in field studies. However, further validation with additional studies is warranted, in order to confirm that the good correspondence is not coincidental but based in our understanding of the processes at play.

\section{Conclusions}

While the solar disinfection of viruses is a well-known phenomenon, it remains difficult to measure in field settings. Here, we therefore present a model to estimate virus inactivation as a function of water quality parameters and geographical location. We demonstrate that photoinactivation trends vary greatly depending on a virus' susceptibility to endogenous and exogenous processes. Specifically, viruses that are mainly inactivated by endogenous inactivation, such as $\phi X 174$, dramatically respond to any change in the UVB portion of the solar irradiance spectrum. As such, their inactivation rapidly decreases at elevated DOC because of competition for sunlight irradiance between virus and organic matter, and at elevated depth because of insufficient illumination of the water column. In addition, their inactivation also rapidly becomes less efficient at higher latitudes as well as during winter months due to the enhanced atmospheric attenuation of UVB. In contrast, viruses with a lower sensitivity to endogenous inactivation but a higher sensitivity to exogenous inactivation, such as MS2, have a more moderate response to changes in water quality parameters, season or geographical location. This is because their inactivation is partly sustained by exogenous processes, which are less affected by changes in the irradiance spectrum. Overall, a virus' susceptibility to endogenous and exogenous inactivation are thus important indicators of their fate in sunlit waters.

We furthermore established that both the extent of inactivation as well as the dominant inactivating processes are largely governed by the content (and source) of DOC. This implies that the complexity of a solar disinfection model can be greatly reduced by focusing solely on an easy-to-measure water quality parameter (DOC). An interesting difference can be noted between WSP water and natural surface water, as far as exogenous inactivation is concerned. Possibly due to the occurrence of less aged organic matter in WSP, one gets a more important contribution of ${ }^{1} \mathrm{O}_{2}$ and a less important one of $\mathrm{CO}_{3}{ }^{-\cdot}$ to inactivation in WSP, compared to natural surface waters.

Our modeling approach yields fairly accurate results compared to measured inactivation rate constants reported in the literature, which suggests a central role of photoinactivation in the overall inactivation of viruses in wastewater-impacted surface water. However, future work should refine the model with respect to several parameters: first, in particular for viruses which are susceptible to oxidation by reactive species, the temperature- and $\mathrm{pH}$ dependence of exogenous inactivation should be accounted for. Second, for inactivation in marine systems, the role of ionic strength and halide species should be further investigated and included in the model. Third, the role of organic matter-virus interaction needs to be considered. 
Finally, the model should be generalized to other viruses not considered herein, and for which no kinetic parameters exist as model inputs. This last point is arguably the most challenging, as it is not well understood which parameters render a virus susceptible to solar disinfection. However, as illustrated by our model results, endogenous processes often contribute importantly to total photoinactivation. As demonstrated by Lytle and Sagripanti (2005), it may be feasible to predict the susceptibility to endogenous inactivation based on a specific virus' genome length and composition. While such predictions need further confirmation and expansion to include exogenous processes, they nevertheless illustrate that a complete model to predict the solar disinfection of any virus may be a reasonable goal.

\section{Acknowledgments}

This study was supported by EPFL and by the Swiss National Science Foundation (project numbers 118077 and 131918). DV acknowledges financial support by Università di Torino - EU Accelerating Grants, project TO_Call2_2012_0047 (DOMNAMICS).

\section{Appendix A. Supplementary data}

Supplementary data related to this article can be found at http:// dx.doi.org/10.1016/j.watres.2015.11.022.

\section{References}

Al Housari, F., Vione, D., Chiron, S., Barbati, S., 2010. Reactive photoinduced species in estuarine waters. Characterization of hydroxyl radical, singlet oxygen and dissolved organic matter triplet state in natural oxidation processes. Photochem. Photobiol. Sci. 9 (1), 78-86. http://dx.doi.org/10.1039/b9pp00030e.

Avetta, P., Marchetti, G., Minella, M., Pazzi, M., De Laurentiis, E., Maurino, V., Minero, C., Vione, D., 2014. Phototransformation pathways of the fungicide dimethomorph ((E,Z) 4-[3-(4-chlorophenyl)-3-(3,4-dimethoxyphenyl)-1-oxo2-propenyl]morpholine), relevant to sunlit surface waters. Sci. Total Environ. 500-501, 351-360. http://dx.doi.org/10.1016/j.scitotenv.2014.08.067.

Bodrato, M., Vione, D., 2014. APEX (aqueous photochemistry of environmentally occurring xenobiotics): a free software tool to predict the kinetics of photochemical processes in surface waters. Enviro. Sci. Process. Impacts 16 (4), 732-740. http://dx.doi.org/10.1039/c3em00541k.

Boehm, A.B., Yamahara, K.M., Love, D.C., Peterson, B.M., McNeill, K., Nelson, K.L., 2009. Covariation and photoinactivation of traditional and novel indicator organisms and human viruses at a sewage-impacted marine beach. Environ. Sci. Technol. 43 (21), 8046-8052. http://dx.doi.org/10.1021/es9015124.

Bosshard, F., Armand, F., Hamelin, R., Kohn, T., 2013. Mechanisms of human adenovirus inactivation by sunlight and UVC light as examined by quantitative PCR and quantitative proteomics. Appl. Environ. Microbiol. 79 (4), 1325-1332. http://dx.doi.org/10.1128/AEM.03457-12.

Boule, P., Bahnemann, D.W., Robertson, P.K.J., 2005. The Handbook of Environmental Chemistry vol. 2M - Environmental Photochemistry Part II. Springer, Berlin, p. 489.

Braslavsky, S.E., 2007. Glossary of terms used in photochemistry, 3rd edition (IUPAC recommendations 2006). Pure Appl. Chem. 79 (3), 293-465. http://dx.doi.org/ 10.1351/pac200779030293.

Canonica, S., Kohn, T., Mac, M., Real, FJ., Wirz, J., von Gunten, U, 2005. Photosensitizer method to determine rate constants for the reaction of carbonate radical with organic compounds. Environ. Sci. Technol. 39 (23), 9182-9188.

Carratalà, A., Dionisio Calado, A., Mattle, M.J., Meierhofer, T., Luzi, S., Kohn, T., 2015. Solar Disinfection (SODIS) of Viruses in PET Bottles. http://dx.doi.org/10.1128 AEM.02897-15.

Davies-Colley, R.J., Donnison, A.M., Speed, D.J., 2000. Towards a mechanistic understanding of pond disinfection. Water Sci. Technol. 42 (10-11), 149-158.

Davies-Colley, R.J., Donnison, A.M., Speed, D.J., Ross, C.M., Nagels, J.W., 1999. Inactivation of faecal indicator micro-organisms in waste stabilisation ponds: interactions of environmental factors with sunlight. Water Res. 33 (5), 1220-1230. http://dx.doi.org/10.1016/S0043-1354(98)00321-2.

De Laurentiis, E., Buoso, S., Maurino, V., Minero, C., Vione, D., 2013. Optical and photochemical characterization of chromophoric dissolved organic matter from lakes in Terra Nova Bay, Antarctica. Evidence of considerable photoreactivity in an extreme environment. Environ. Sci. Technol. 47 (24), 14089-14098. http:// dx.doi.org/10.1021/es403364z.

Fisher, M.B., Love, D.C., Schuech, R., Nelson, K.L., 2011. Simulated sunlight action spectra for inactivation of MS2 and PRD1 bacteriophages in clear water.
Environ. Sci. Technol. 45 (21), 9249-9255. http://dx.doi.org/10.1021/es201875x.

Fong. T. Lipp, E., 2005. Enteric viruses of humans and animals in aquatic environments: health risks, detection, and potential water quality assessment tools. Microbiol. Mol. Biol. Rev. 69 (2), 357-371. http://dx.doi.org/10.1128/ MMBR.69.2.357.

Frank, R., Klöpffer, W., 1988. Spectral solar photon irradiance in Central Europe and the adjacent North Sea. Chemosphere 17 (5), 985-994. http://dx.doi.org/ 10.1016/0045-6535(88)90069-0.

Kohn, T., Grandbois, M., McNeill, K., Nelson, K.L., 2007. Association with natural organic matter enhances the sunlight-mediated inactivation of MS2 coliphage by singlet oxygen. Environ. Sci. Technol. 41 (13), 4626-4632.

Kohn, T., Nelson, K.L., 2007. Sunlight-mediated inactivation of MS2 coliphage via exogenous singlet oxygen produced by sensitizers in natural waters. Environ. Sci. Technol. 41 (1), 192-197. http://dx.doi.org/10.1021/es061716i.

Loiselle, S., Vione, D., Minero, C., Maurino, V., Tognazzi, A., Dattilo, A.M., Rossi, C., Bracchini, L., 2012. Chemical and optical phototransformation of dissolved organic matter. Water Res. 46 (10), 3197-3207. http://dx.doi.org/10.1016/ j.watres.2012.02.047.

Loiselle, S.A., Azza, N., Cozar, A., Bracchini, L., Tognazzi, A., Dattilo, A., Rossi, C., 2008. Variability in factors causing light attenuation in Lake Victoria. Freshw. Biol. 53 (3), 535-545. http://dx.doi.org/10.1111/j.1365-2427.2007.01918.x.

Lytle, C.D., Sagripanti, J.-L., 2005. Predicted inactivation of viruses of relevance to biodefense by solar radiation. J. Virol. 79 (22), 14244-14252. http://dx.doi.org/ 10.1128/JVI.79.22.14244-14252.2005.

Maddigapu, P.R., Minella, M., Vione, D., Maurino, V., Minero, C., 2011. Modeling phototransformation reactions in surface water bodies: 2,4-dichloro-6-nitrophenol as a case study. Environ. Sci. Technol. 45 (1), 209-214. http://dx.doi.org/ 10.1021/es102458n.

Marchetti, G., Minella, M., Maurino, V., Minero, C., Vione, D., 2013. Photochemical transformation of atrazine and formation of photointermediates under conditions relevant to sunlit surface waters: laboratory measures and modelling. Water Res. 47 (16), 6211-6222. http://dx.doi.org/10.1016/j.watres.2013.07.038.

Mattle, M.J., Vione, D., Kohn, T., 2015. Conceptual model and experimental framework to determine the contributions of direct and indirect photoreactions to the solar disinfection of MS2, phiX174, and adenovirus. Environ. Sci. Technol. 49 (1), 334-342. http://dx.doi.org/10.1021/es504764u.

Montenbruck, O., Pfleger, T., 1994. Astronomy on the Personal Computer, second ed. Springer Verlag, Berlin.

National Center for Atmospheric Research, 2015. Quick TUV Calculator [WWW Document]. http://cprm.acom.ucar.edu/Models/TUV/Interactive_TUV/ (accessed 5.20.06.).

Okoh, A.I., Sibanda, T., Gusha, S.S., 2010. Inadequately treated wastewater as a source of human enteric viruses in the environment. Int. J. Environ. Res. Public Health 7 (6), 2620-2637. http://dx.doi.org/10.3390/ijerph7062620.

Rauth, A., 1965. The physical state of viral nucleic acid and the sensitivity of viruses to ultraviolet light. Biophys. J. 5 (3), 257-273. http://dx.doi.org/10.1016/S00063495(65)86715-7.

Romero, O.C., Straub, A.P., Kohn, T., Nguyen, T.H., 2011. Role of temperature and Suwannee river natural organic matter on inactivation kinetics of rotavirus and bacteriophage MS2 by solar irradiation. Environ. Sci. Technol. 45 (24), 10385-10393. http://dx.doi.org/10.1021/es202067f.

Romero-Maraccini, O.C., Sadik, N.J., Rosado-Lausell, S.L., Pugh, C.R., Niu, X.-Z., Croué, J.-P., Nguyen, T.H., 2013. Sunlight-induced inactivation of human Wa and porcine OSU rotaviruses in the presence of exogenous photosensitizers. Environ. Sci. Technol. 47 (19), 11004-11412. http://dx.doi.org/10.1021/es402285u.

Silverman, A.I., Nguyen, M.T., Schilling, I.E., Wenk, J., Nelson, K.L., 2015. Sunlight inactivation of viruses in open-water unit process treatment wetlands: modeling endogenous and exogenous inactivation rates. Environ. Sci. Technol. 49 (5), 2757-2766. http://dx.doi.org/10.1021/es5049754.

Silverman, A.I., Peterson, B.M., Boehm, A.B., McNeill, K., Nelson, K.L., 2013. Sunlight inactivation of human viruses and bacteriophages in coastal waters containing natural photosensitizers. Environ. Sci. Technol. 47 (4), 1870-1878. http:// dx.doi.org/10.1021/es3036913.

Simmons, F.J., Xagoraraki, I., 2011. Release of infectious human enteric viruses by full-scale wastewater utilities. Water Res. 45 (12), 3590-3598. http:// dx.doi.org/10.1016/j.watres.2011.04.001.

Sinton, L.W., Hall, C., Lynch, P.A., Davies-Colley, R.J., 2002. Sunlight inactivation of fecal indicator bacteria and bacteriophages from waste stabilization pond effluent in fresh and saline waters. Appl. Environ. Microbiol. 68 (3), 1122-1131. http://dx.doi.org/10.1128/AEM.68.3.1122.

Sommer, R., Pribil, W., Appelt, S., Gehringer, P., Eschweiler, H., Leth, H., Cabaj, A., Haider, T., 2001. Inactivation of bacteriophages in water by means of nonionizing (UV-253.7 nm) and ionizing (gamma) radiation: a comparative approach. Water Res. 35 (13), 3109-3116. http://dx.doi.org/10.1016/s00431354(01)00030-6.

Thurman, E.M., 2012. Organic Geochemistry of Natural Waters. Springer Science \& Business Media.

UN, 2015. http://www.un.org/sustainabledevelopment/water-and-sanitation/ (last accessed November 2015).

Verbyla, M.E., Mihelcic, J.R., 2014. A review of virus removal in wastewater treatment pond systems. Water Res. 71, 107-124. http://dx.doi.org/10.1016/ j.watres.2014.12.031.

Vione, D., 2014. A test of the potentialities of the APEX software (aqueous 
photochemistry of environmentally occurring xenobiotics). Modelling the photochemical persistence of the herbicide cycloxydim in surface waters, based on literature kinetic data. Chemosphere 99, 272-275. http://dx.doi.org/10.1016/ j.chemosphere.2013.10.078.
Wigginton, K.R., Pecson, B.M., Sigstam, T., Bosshard, F., Kohn, T., 2012. Virus inactivation mechanisms: impact of disinfectants on virus function and structural integrity. Environ. Sci. Technol. 46 (21), 12069-12078. http://dx.doi.org/ 10.1021/es3029473. 